\title{
Recent insights into the biology of bone turnover
}

\author{
${ }^{1}$ PL Riches, ${ }^{2} \mathrm{SH}$ Ralston \\ ${ }^{1}$ Rheumatology Consultant; ${ }^{2}$ ARC Professor of Rheumatology, Institute of Genetics and Molecular Medicine, Western General Hospital, Edinburgh, UK
}

This review is based on the Croom Lecture delivered by Dr Riches at the RCPE Updates in Internal Medicine Symposium on 23 October 2009.

\section{KEYWORDS Osteoporosis, osteoprotegerin, RANK, RANK ligand}

DECLARATION OF INTERESTS The authors have submitted a patent application on the use of osteoprotegerin antibodies as a diagnostic test and therapeutic target in patients with osteoporosis. Professor Ralston has received consulting fees from Procter \& Gamble and Novartis and Merck, lecture fees from Novartis and Procter \& Gamble and grant support from Novartis and Wyeth.

\author{
Correspondence to PL Riches, \\ Institute of Genetics and \\ Molecular Medicine, \\ Western General Hospital, \\ Edinburgh EH4 2XU, UK
}

tel. $+44(0) 1316511022$ e-mail priches@staffmail.ed.ac.uk

\section{INTRODUCTION}

The maintenance of healthy bone is an active process involving both resorption of bone by osteoclasts and the laying down of new bone by osteoblasts. It is estimated that the entire skeleton is reformed over a period of 10 to 20 years. The receptor activator of nuclear factor kappa B (RANK) pathway was identified more than ten years ago as the key regulator of osteoclast activation and cross talk between osteoblasts and osteoclasts. ${ }^{1,2}$ The RANK receptor is a member of the tumour necrosis factor (TNF) receptor superfamily which is expressed on osteoclast precursors and dendritic cells, with RANK ligand (RANKL) expressed on bone marrow stromal cells and lymphocytes, ${ }^{3,4}$ thereby representing an intriguing link between bone homeostasis and immune regulation.

\section{THE ROLE OF THE RANK PATHWAY IN THE REGULATION OF BONE TURNOVER}

The RANK signalling pathway plays a critical role in regulating bone mass and bone turnover. Activation of RANK signalling in osteoclast precursors occurs on the binding of RANKL expressed by bone marrow stromal cells and activated T-cells (Figure I), or by the binding of a soluble ligand (sRANKL) which is formed by cleavage of RANKL from the cell membrane. ${ }^{5}$ This causes the activation of several intracellular signalling pathways, including the transcription factor nuclear factor kappa $B$ (NF $\kappa$ B), which promote maturation and activation of osteoclasts, and consequently bone resorption. As bone marrow stromal cells mature into osteoblasts their expression of RANKL reduces, and secretion of osteoprotegerin increases, downregulating osteoclast activity and promoting bone formation. ${ }^{6}$ Osteoprotegerin (OPG) is a decoy receptor for RANKL, which inhibits bone resorption by blocking its interaction with RANK (Figure I). The essential requirement of RANK signalling for osteoclast development is demonstrated by the fact that mice with targeted inactivation of the RANK and RANKL genes develop very high bone density (osteopetrosis) due to failure of osteoclast

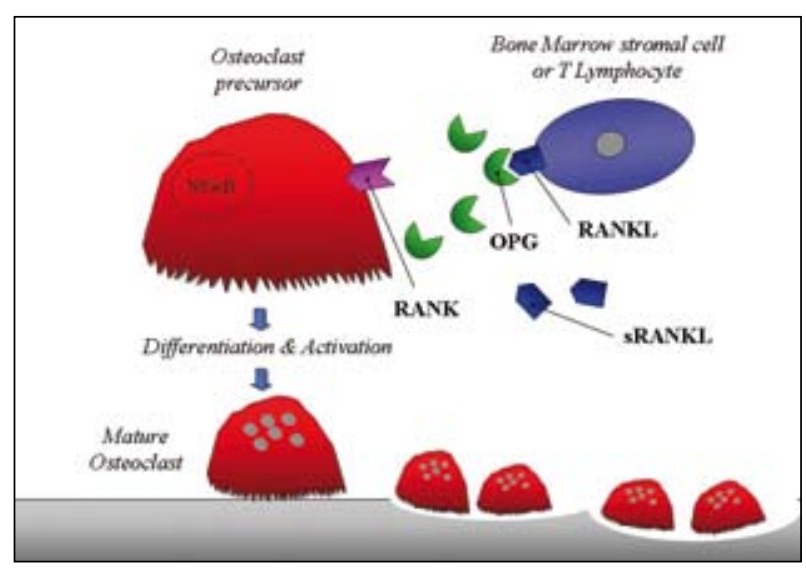

FIGURE I The role of the receptor activator of nuclear factor kappa B (RANK) pathway in osteoclast development.

RANK ligand (RANKL) expressed by bone marrow stromal cells or $T$ lymphocytes induces differentiation and activation of osteoclast precursors via RANK and subsequent activation of nuclear factor kappa B (NFKB). Soluble RANKL (sRANKL) is derived by cleavage from the cell membrane. Osteoprotegerin (OPG), a soluble inhibitor of RANKL, inhibits the binding of RANK by RANKL.

differentiation. ${ }^{7,8}$ Although many factors have been shown to contribute to osteoclastogenesis, including interleukin-I (IL-I); transforming growth factor (TGF) beta; TNF; IL-6; I,25; vitamin D3; and parathyroid hormone, the effects of these agents on osteoclast activity have been shown at least in part to be mediated by alteration of the RANK signalling pathway. ${ }^{9}$

\section{DISTURBANCE OF THE RANK SIGNALLING PATHWAY IN DISEASE}

\section{Osteopetrosis}

Osteopetrosis is the term given to a rare group of genetic diseases characterised by defects in osteoclast differentiation or function. Patients typically develop increased bone density with a paradoxical increase in bone fragility. Examination of bone biopsies allows the identification of 'osteoclast rich' and 'osteoclast poor' subtypes. Recent studies have shown that many patients 
with 'osteoclast poor' recessive osteopetrosis have loss of function mutations in the genes which encode RANK and RANKL, resulting in a failure of osteoclast differentiation. ${ }^{10}$

\section{Inflammation-induced bone loss}

Osteoporosis is a recognised complication of autoimmune diseases such as coeliac disease," inflammatory bowel disease $^{12}$ and inflammatory rheumatic diseases, including rheumatoid arthritis. ${ }^{13}$ It has been attributed to multiple mechanisms, including local and systemic inflammation and corticosteroid therapy.11,14 In coeliac disease specifically, reduced bone density (osteopaenia) is found in up to $40 \%$ of patients at presentation and correlates poorly with severity of disease, emphasising that this is not a simple consequence of malabsorption." A wealth of data now exists that explains many of these effects via alteration of the RANK signalling axis. Activated T-cells express RANKL directly, and this mediates bone loss and joint destruction that can be blocked by administering recombinant OPG. ${ }^{15}$ Similarly, in rheumatoid arthritis the blockade of RANKL has been shown to impede the development of bone erosions. ${ }^{16}$ Inflammatory cytokines such as IL-6 or TNF are correlated with levels of RANKL or increased RANKL/OPG in rheumatoid arthritis, coeliac disease and inflammatory bowel disease. ${ }^{17,18}$ Glucocorticoid therapy has been shown to directly inhibit OPG and stimulate RANKL in osteoblasts. ${ }^{19}$

Several investigators have looked for evidence of associations between circulating levels of OPG and/or sRANKL and osteoporosis associated with inflammatory disease. The results of these studies have been surprising in paradoxically showing an association between low sRANKL levels or high circulating OPG levels and osteoporosis. $^{20,21}$ Rationalising this difference, many authors have emphasised the paracrine rather than endocrine action of these factors on cellular function, or alternatively have suggested that this is a compensatory mechanism attempting to restore bone homeostasis. It is important to recognise that OPG and sRANKL are produced by diverse cell types, hence the circulating levels may bear little correlation with the bone microenvironment, ${ }^{21-23}$ and that there exists significant variability within currently available assays for sRANKL. ${ }^{22}$

\section{Paget's disease}

Paget's disease of bone (PDB) is a common metabolic bone disease that affects about $3 \%$ of individuals over the age of 55 in the UK. ${ }^{24}$ Paget's disease is characterised by focal areas of increased osteoclastic bone resorption, coupled to increased and disorganised bone formation. The cause of PDB is incompletely understood, but accumulating evidence suggests that genetic factors play a major role. ${ }^{25}$ Over the past five years it has become clear that mutations in genes within the RANK pathway play a key role in the pathogenesis of PDB and related disorders. Activating mutations of the TNFRSFI IA gene which encodes RANK have been identified as the cause of the rare bone dysplasias, familial expansile osteolysis, expansile skeletal hyperplasia and early onset familial PDB. ${ }^{26-28}$ Similarly, loss of function mutations in the TNFRSFI IB gene encoding OPG cause 'juvenile Paget's disease', a rare disease characterised by high bone turnover, bone deformity and multiple fractures. ${ }^{29}$

Mutations in the SQSTM I gene have now been identified as the most important cause of PDB, accounting for up to $40 \%$ of familial and II\% of sporadic PDB cases. SQSTMI encodes a scaffold protein involved in NFKB signalling downstream of RANK, explaining its effect on osteoclastic bone resorption. ${ }^{30}$ Finally, mutations in the valosin-containing protein (VCP) gene cause the syndrome of inclusion body myopathy, PDB and fronto-temporal dementia. Once again the effect on bone can be explained by the involvement of the VCP gene in NFKB signalling; this appears to be mediated by targeting the inhibitor of NF kappa B (lkB) for degradation by the proteasome. ${ }^{30}$

\section{Osteoporosis}

There is increasing evidence that common genetic variants in the TNFRSFIIA, TNFRSFIIB and TNFSFII genes encoding RANK, OPG and RANKL respectively play a role in the regulation of bone mass and susceptibility to osteoporotic fractures. ${ }^{31}$ Oestrogen deficiency is a key risk factor for post-menopausal osteoporosis, which is partially explained by oestrogen's demonstrated ability to enhance OPG production by osteoblasts. ${ }^{32}$

Investigators have looked for evidence of associations between circulating levels of OPG and/or sRANKL and post-menopausal osteoporosis, but again paradoxically there are reports of high circulating OPG levels and low sRANKL levels in patients with osteoporosis. ${ }^{33}$

Recently, a novel mechanism of osteoporosis has been described due to the development of neutralising antibodies to OPG. ${ }^{34}$ These antibodies block the inhibitory effect of OPG on RANK signalling (Figure 2). The index case was a 40-year-old man who presented with a low trauma fracture and severe osteoporosis (lumbar spine T score of -6.6). He was found to have coeliac disease and autoimmune hypothyroidism, but his osteoporosis deteriorated despite appropriate treatment of these conditions and calcium and vitamin D supplements. At baseline the patient was found to have markedly elevated bone turnover, with serum alkaline phosphatase levels 20 times above the upper limit of normal and collagen breakdown product deoxypyridinoline values also 20 times above the upper limit of normal in urine samples. On bone biopsy he was found to have greatly increased numbers of osteoclasts. He was eventually treated with zoledronic acid, which restored levels of bone turnover and increased bone mineral density values to within the normal range. 
a

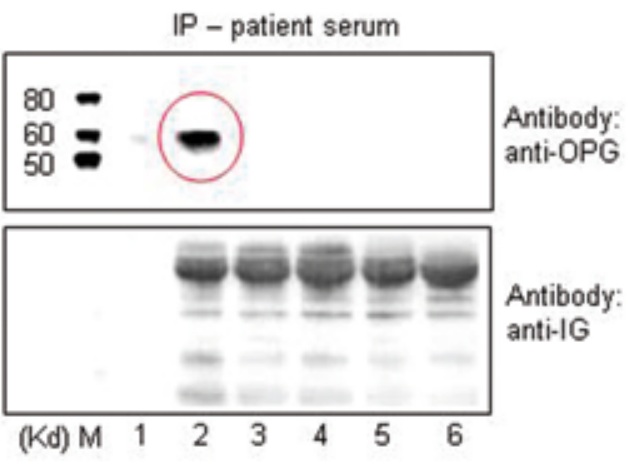

$b$

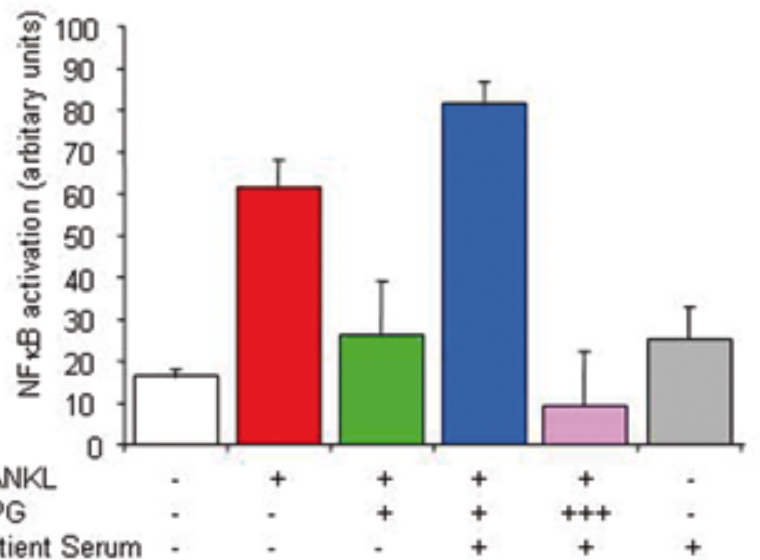

FIGURE 2 Identification of neutralising antibodies to osteoprotegerin.

a) Recognition of OPG by serum from the index patient (lane 2) but not controls (lanes 3-6) demonstrated by immunoprecipitation assay. Lane I is a negative control. The bottom panel is probed with an anti-immunoglobulin antibody demonstrating equal loading. b) Blockade of the inhibitory effect of OPG on RANK signalling by patient serum in vitro. RANK stimulation by RANKL ( $100 \mathrm{ng} / \mathrm{ml})$ is demonstrated in human embryonal kidney-derived cells (HEK293) stably expressing a NFKB reporter vector (red). The addition of OPG $(100 \mathrm{ng} / \mathrm{ml})$ blocks this signalling (green). Patient serum (I/40 dilution) reversed this inhibition (blue), but this could be overcome by the addition of excess OPG (400 $\mathrm{ng} / \mathrm{ml}$ ) (purple). There was no effect on signalling in the absence of RANKL stimulation (grey).

(Reproduced with kind permission of the New England Journal of Medicine.)

Autoantibodies to OPG were found in about $20 \%$ of a small cohort of patients with coeliac disease. ${ }^{34}$ This raises the possibility that these antibodies might contribute to the pathogenesis of osteoporosis in coeliac disease more widely, although the clinical relevance of these findings remains to be established.

\section{CLINICAL IMPLICATIONS}

The identification of the RANK pathway has opened up novel therapeutic targets in the management of osteoporosis. An Fc-OPG construct showed effectiveness in reducing bone turnover, ${ }^{35}$ although this is no longer being developed in clinical trials. More recently denosumab, a fully humanised anti-RANKL antibody has shown effectiveness in the treatment of post-menopausal osteoporosis. ${ }^{36}$ Alternatively, the signalling cascade induced by RANK binding may be targeted by small molecule inhibitors, as has been demonstrated in other members of the TNF superfamily. ${ }^{37}$

\section{REFERENCES}

I Khosla S. Minireview: the OPG/RANKL/RANK system. Endocrinology 200I; I42:5050-5. doi:I0.1210/en. I42.12.5050

2 Lacey DL, Timms E, Tan HL et al. Osteoprotegerin ligand is a cytokine that regulates osteoclast differentiation and activation. Cell 1998; 93:165-76. doi:10.1016/S0092-8674(00)81569-X

3 Hsu H, Lacey DL, Dunstan CR et al. Tumor necrosis factor receptor family member RANK mediates osteoclast differentiation and activation induced by osteoprotegerin ligand. Proc Natl Acad Sci USA 1999; 96:3540-5. doi:I0.1073/pnas.96.7.3540
The observation that neutralising antibodies to OPG cause severe osteoporosis raises the possibility that screening for OPG antibodies, particularly in patients with autoimmune disease, may be a valuable method for detecting patients at risk of osteoporosis and guiding their subsequent management. Such patients would be expected to have high bone turnover and therefore be particularly suitable for treatment with antiresorptive drugs. It is also possible that specific treatments may be developed to block the neutralising antibody itself.

Since RANK signalling has been shown to be a critical regulator of diverse functions such as lymph node organogenesis, ${ }^{7}$ thymic development ${ }^{38}$ and temperature regulation, ${ }^{39}$ there will need to be careful evaluation of any novel therapy targeting this pathway.

4 Theill LE, Boyle WJ, Penninger JM. RANK-L and RANK: T cells, bone loss, and mammalian evolution. Annu Rev Immunol 2002; 20:795-823. doi:I0.I I46/annurev.immunol.20.10030I.064753

5 Blair JM, Zheng Y, Dunstan CR. RANK ligand. Int J Biochem Cell Biol 2007; 39:1077-8I. doi:I0.1016/j.biocel.2006.II.008

6 Gori F, Hofbauer LC, Dunstan CR et al. The expression of osteoprotegerin and RANK ligand and the support of osteoclast formation by stromal-osteoblast lineage cells is developmentally regulated. Endocrinology 2000; 141:4768-76. doi:I0.12 I0/en. I4I.12.4768 
7 Kong YY, Yoshida H, Sarosi I et al. OPGL is a key regulator of osteoclastogenesis, lymphocyte development and lymph-node organogenesis. Nature 1999; 397:315-23. doi:10.1038/I6852

8 Dougall WC, Glaccum M, Charrier $\mathrm{K}$ et al. RANK is essential for osteoclast and lymph node development. Genes Dev 1999; 13:24|2-24. doi:I0.1 I0|/gad. I3.I8.24I/2

9 Leibbrandt A, Penninger JM. RANK/RANKL: regulators of immune responses and bone physiology. Ann NYAcad Sci 2008; I I43:12350. doi:I0.I I96/annals. I443.016

I0 Villa A, Guerrini M, Cassani B et al. Infantile malignant, autosomal recessive osteopetrosis: the rich and the poor. Calcif Tissue Int 2009; 84:I-12. doi:I0.1007/s00223-008-9196-4

I I Bianchi ML, Bardella MT. Bone and celiac disease. Calcif Tissue Int 2002; 7I:465-7I. doi:I0.1007/s00223-00I-2I3I-6

I2 Noble CL, McCullough J, HoW et al. Low body mass not vitamin D receptor polymorphisms predict osteoporosis in patients with inflammatory bowel disease. Aliment Pharmacol Ther 2008; 27:588-96.

I3 Van Staa TP, Geusens P, Bijlsma JW et al. Clinical assessment of the long-term risk of fracture in patients with rheumatoid arthritis. Arthritis Rheum 2006; 54:3104-12. doi:10.1002/art.22117

14 Goldring SR, Gravallese EM. Mechanisms of bone loss in inflammatory arthritis: diagnosis and therapeutic implications. Arthritis Res 2000; 2:33-7. doi:10.1 186/ar67

I5 Kong YY, Feige U, Sarosi I et al. Activated T cells regulate bone loss and joint destruction in adjuvant arthritis through osteoprotegerin ligand. Nature 1999; 402:304-9. doi:10.1038/46303

16 Cohen SB, Dore RK, Lane NE et al. Denosumab treatment effects on structural damage, bone mineral density, and bone turnover in rheumatoid arthritis: a twelve-month, multicenter, randomized, double-blind, placebo-controlled, phase II clinical trial. Arth Rheum 2008; 58:1299-309. doi:10.1002/art.234I7

17 Romas E, Gillespie MT, Martin TJ. Involvement of receptor activator of NFKB ligand and tumor necrosis factor- $\alpha$ in bone destruction in rheumatoid arthritis. Bone 2002; 30:340-6. doi:I0.1016/S8756-3282(0I)00682-2

I8 Taranta A, Fortunati D, Longo M et al. Imbalance of osteoclastogenesisregulating factors in patients with celiac disease. J Bone Miner Res 2004; 19: I | |2-21. doi: I0. I359/JBMR.0403 I9

19 Hofbauer LC, Gori F, Riggs BL et al. Stimulation of osteoprotegerin ligand and inhibition of osteoprotegerin production by glucocorticoids in human osteoblastic lineage cells: potential paracrine mechanisms of glucocorticoid-induced osteoporosis. Endocrinology 1999; 140:4382-9. doi: 10.12 I0/en. I40.10.4382

20 Bezerra MC, Calomeni GD, Caparbo VF et al. Low bone density and low serum levels of soluble RANK ligand are associated with severe arterial calcification in patients with Takayasu arteritis. Rheumatology 2005; 44:I503-6. doi: 10.1093/rheumatology/kei045

21 Moschen AR, Kaser A, Enrich B et al.The RANKL/OPG system is activated in inflammatory bowel disease and relates to the state of bone loss. Gut 2005; 54:479-87. doi: I0.1 I36/gut.2004.044370

22 Rogers A, Eastell R. Circulating osteoprotegerin and receptor activator for nuclear factor $\kappa \mathrm{B}$ ligand: clinical utility in metabolic bone disease assessment. J Clin Endocrinol Metab 2005; 90:6323-3I. doi:10.1210/jc.2005-0794

23 Findlay D, Chehade $M$, Tsangari $\mathrm{H}$ et al. Circulating RANKL is inversely related to RANKL mRNA levels in bone in osteoarthritic males. Arthritis Res Ther 2008; I0:R2. doi:I0.I I86/ar2348
24 Cooper C, Schafheutle K, Dennison E et al. The epidemiology of Paget's disease in Britain: is the prevalence decreasing? J Bone Miner Res 1999; 14:192-7. doi: 10.1359/jbmr.1999.14.2.192

25 Daroszewska A, Ralston SH. Genetics of Paget's disease of bone. Clin Sci (Lond) 2005; 109:257-63. doi:I0.I042/CS20050053

26 Hughes AE, Ralston SH, Marken J et al. Mutations in TNFRSFI IA, affecting the signal peptide of RANK, cause familial expansile osteolysis. Nat Genet 2000; 24:45-8. doi: 10.1038/7I667

27 Nakatsuka K, Nishizawa Y, Ralston SH. Phenotypic characterization of early onset Paget's disease of bone caused by a 27-bp duplication in the TNFRSFIIA gene. J Bone Miner Res 2003; I8:I38I-5. doi:10.1359/jbmr.2003.18.8.138|

28 Whyte MP, Hughes AE. Expansile skeletal hyperphosphatasia is caused by a I5-base pair tandem duplication in TNFRSFIIA encoding RANK and is allelic to familial expansile osteolysis.J Bone Miner Res 2002; 17:26-9. doi:I0.1359/jbmr.2002.17.I.26

29 Chong B, Hegde M, Fawkner M et al. Idiopathic hyperphosphatasia and TNFRSFI IB mutations: relationships between phenotype and genotype. J Bone Miner Res 2003; 18:2095-104. doi:I0.I359| jbmr.2003.18.12.2095

30 Ralston SH, Langston AL, Reid IR. Pathogenesis and management of Paget's disease of bone. Lancet 2008; 372:155-63. doi:10.1016/ S0I40-6736(08)6I035-I

3I Rivadeneira F, Styrkársdottir U, Estrada $\mathrm{K}$ et al. Twenty bonemineral-density loci identified by large-scale meta-analysis of genome-wide association studies. Nat Genet 2009; 41:1199-206. doi:10.1038/ng.446

32 Bord S, Ireland DC, Beavan SR et al. The effects of estrogen on osteoprotegerin, RANKL, and estrogen receptor expression in human osteoblasts. Bone 2003; 32:|36-4I. doi:I0.10|6/S87563282(02)00953-5

33 Yano K, Tsuda $\mathrm{E}, \mathrm{W}$ ashida $\mathrm{N}$ et al. Immunological characterization of circulating osteoprotegerin/osteoclastogenesis inhibitory factor: increased serum concentrations in postmenopausal women with osteoporosis. J Bone Miner Res 1999; 14:518-27. doi:10.1359/ jbmr.1999.14.4.518

34 Riches PL, McRorie E, Fraser WD et al. Osteoporosis associated with neutralizing autoantibodies against osteoprotegerin. $N$ Engl J Med 2009; 36I:|459-65. doi:I0.1056/NEJMoa0810925

35 Bekker PJ, Holloway D, Nakanishi A et al. The effect of a single dose of osteoprotegerin in postmenopausal women.J Bone Miner Res 200I; 16:348-60. doi:I0.I359/jbmr.200I.16.2.348

36 Cummings SR, Martin JS, McClung MR et al. Denosumab for prevention of fractures in postmenopausal women with osteoporosis. N Engl J Med 2009; 36I:756-65. doi:10.1056/ NEJMoa0809493

37 He MM, Smith AS, Oslob JD et al. Small-molecule inhibition of TNF- $\alpha$. Science 2005; 310:1022-5. doi: I0.I I26/science. I I 16304

38 Akiyama T, Shimo Y, Yanai $\mathrm{H}$ et al. The tumor necrosis factor family receptors RANK and CD40 cooperatively establish the thymic medullary microenvironment and self-tolerance. Immunity 2008; 29:423-37. doi:10.1016/j.immuni.2008.06.015

39 Hanada R, Leibbrandt A, Hanada T et al. Central control of fever and female body temperature by RANKL/RANK. Nature 2009; 462:505-9. doi:10.1038/nature08596 